\title{
Cosecheros de tabaco de Simojovel a fines del Siglo XVIII y albores del XIX
}

\author{
Simojovel Tobacco Growers of the Late Eighteenth and Early Nineteenth Centuries
}

\author{
Carlos Uriel del Carpio-Penagos
}

Resumen: Mediante fuentes de primera mano localizadas en Sevilla y en Guatemala se estudia el funcionamiento del Estanco del Tabaco en la Audiencia de Guatemala, las unidades productivas de tabaco y su composición social, así como los cambios técnicos en el cultivo de este producto a fines del siglo XVIII y principios del XIX en Simojovel, Chiapas. Esta actividad introdujo en el municipio la propiedad privada de la tierra e inició la desaparición de la propiedad comunal indígena. Se sostiene que la ubicación del pueblo en un camino muy transitado entre Ciudad Real y Tabasco fue un aliciente para inmigrantes que llegaron atraídos por el cultivo de la hierba y por la perspectiva de hacer negocios legales o de contrabando, lo que convirtió a Simojovel en un centro de mestizaje y transculturación.

Palabras clave: tabaco, producción agrícola, productores, historia social, historia económica.

Abstract: By accessing first-hand sources in Seville and in Guatemala I studied the functioning of the oficial tobacco monopoly, the size of tobacco-producing units, their social composition, and the technical changes that occurred in this area during the late 18th century and early 19th century in Simojovel, Chiapas, Mexico. This activity led to private property land-holding within the municipality, which in turn led to the disappearance of former communally-held land parcels among the indigenous "ejido" members. We claim that because the town was located on a well-traveled route between Ciudad Real and Tabasco, immigrants were attracted to settle there by the existing cultivation of tobacco, and by the prospect of setting up legal or contraband business ventures, thus converting Simojovel into a center of racial and cultural mixing.

Keywords: tobacco, agricultural production, agricultural producers, social history, economic history.

Carlos Uriel del Carpio Penagos. Doctor en ciencias en ecología y desarrollo sustentable por El Colegio de la Frontera Sur, México. Profesor-investigador en la Universidad de Ciencias y Artes de Chiapas y profesor de la Facultad de Arquitectura de la Universidad Autónoma de Chiapas, México. Temas de especialización: formación histórica de las fronteras políticas en Centroamérica, manejo de recursos naturales en áreas de fronteras políticas, e historia y cultura de Centroamérica. Correo electrónico: carlitosuriel@hotmail.com.

Enviado a dictamen: 16 de enero de 2017. Aprobación: 29 de septiembre de 2017. Revisiones: 1. 
L a relevancia del tabaco para la economía de la Audiencia de Guatemala es indudable; era el obtenía ingresos, después del tributo indígena y del impuesto al comercio denominado "alcabala" (Del Carpio, 2014: 196). ${ }^{1}$ Otro indicador de la relevancia del tabaco procede de la información documental sobre esta actividad, muy abundante en los archivos coloniales. Con base en el número de cajones y el número de fichas por cajón, estimo que sólo en el Archivo General de Centroamérica (AGCA) hay alrededor de 14000 documentos sobre el tema. Ningún otro tiene tantos.

Pese a ello, la producción académica sobre el cultivo de tabaco en Centroamérica durante la época del estanco (1766-1821) es prácticamente nula, especialmente en lo que se refiere a Chiapas. El más conocido trabajo es de Jorge Luján Muñoz, publicado en el número 41 de la revista Mesoamérica (junio 2001), donde el autor estudia el estanco en la Audiencia de Guatemala durante su primera década de funcionamiento. Otro trabajo importante sobre el tema es la tesis de licenciatura de Víctor Hugo Acuña Ortega que lleva por título Historia económica del tabaco. Época colonial, presentada en la Universidad de Costa Rica (1974). Dicho trabajo resulta interesante ya que en él su autor muestra cómo en Costa Rica, a diferencia del resto de la Audiencia, el monopolio del Estado colonial sobre el tabaco no implicó un control tan férreo, lo que permitía a comerciantes particulares intermediar entre los cosecheros y el estanco; este último proporcionaba habilitaciones a los agricultores, se encargaba de la compra y el comercio, e incluso permitía que lo exportaran a Panamá (Acuña, 1974: 288). En el caso de Nueva España existe una espléndida obra que, por su acuciosidad y profundidad, constituye un tratado sobre el tema; se trata de Burócratas, cosecheros y trabajadores. La formación del monopolio del tabaco en la Nueva España, de Susan Dean-Smith, libro publicado en 2014 por la Universidad Veracruzana en el que la autora estudia tanto los aspectos institucionales y financieros de la actividad, como el abasto de papel para su temprana industrialización, los productores y comerciantes de Córdoba y Orizaba, el funcionamiento de las fábricas de cigarrillos, la organización del trabajo, las relaciones y conflictos entre los cosecheros y la participación del Estado colonial en la actividad.

En el caso de Chiapas, en un trabajó anterior analicé el Estanco del Tabaco en la Audiencia de Guatemala en diferentes escalas: su establecimiento, su organización interna, las áreas de cultivo, las calidades y precios de las variedades del tabaco, y la resistencia de las autoridades del más alto nivel y de los cosecheros del valle de Copán, en la Provincia de Gracias, Honduras, al establecimiento del estanco, entre otros temas (Del Carpio, 2014: 196). También analicé la transformación de la oficina establecida en Ciudad Real en 1766, que pasó de ser un fielato con media docena de empleados a convertirse, en 1782, en una factoría con dieciséis empleados permanentes y más de un centenar de trabajadores eventuales indígenas originarios de Zinacantán y San Felipe, y algunos mestizos de Ciudad Real. Además, cientos de trabajadores originarios de Chenalhó, Chamula, Tenejapa y otros pueblos tseltales y tsotsiles eran utilizados como cargadores para transportar el producto de Simojovel a Ciudad Real, así como de esta ciudad a Quetzaltenango, Guatemala. En especial se empleaba para esto último a los zinacantecos, que formaban mancuernas con sus mulas parallevar la hierba ya beneficiada, a través de un áspero camino montañoso de más de trescientos kilómetros en el que muchos de ellos o sus animales morían. Además de estos trabajadores directos, había un grupo de transportistas, algunos con varias decenas de mulas manejadas por numerosos arrieros, que llevaban el tabaco desde Ciudad Real a las diversas tercenas de Chiapas y el Soconusco (Del Carpio, 2016: 25). Probablemente ninguna actividad económica de la época en la Audiencia de Guatemala involucraba a tantas personas, por lo menos de manera simultánea.

Por otra parte, se desarrollaba un activo contrabando operado por algunos funcionarios de la renta, pero también por los mismos cosecheros y, en los últimos años de la Colonia, por comerciantes que penetraban a través del río Tonalá y sus numerosos afluentes, y de lagunas del oriente de Veracruz y el oeste de Tabasco. El tabaco era una mercancía que tenía una gran demanda dentro y fuera de la Audiencia, y su producción y comercio eran monopolio real desde Nueva España 
hasta el Río de la Plata, por lo que su contrabando siempre fue atractivo ya que, a pesar de ser riesgoso, producía altas ganancias.

En la Audiencia de Guatemala, el funcionamiento del Estanco del Tabaco fue posible por la creación de una burocracia paralela a la ya existente, la cual llegó a gozar de privilegios especiales y una jurisdicción amplia. Al principio, los puestos de mando de la renta fueron ocupados por alcaldes mayores, corregidores y gobernadores de los pueblos, pero rápidamente esa estructura fue sustituida por empleados que respondían al mandato del director general, y no al presidente de la Audiencia.

Hubo funcionarios de la estructura burocrática de la Audiencia que asumieron puestos dentro de la nueva estructura, como don Tiburcio Ángel de Toledo, quien antes de ocupar el cargo de director general de la Renta del Tabaco en 1768 fungió como alcalde mayor de Totonicapán y Huehuetenango. Fue precisamente él quien promovió la separación de las funciones de la renta de manos de los alcaldes mayores, corregidores y otros empleados de la Audiencia, ya que éstos no reconocían al director general como un oficial superior, por formar parte de una estructura cuya principal figura de autoridad era el presidente de la Audiencia. ${ }^{2}$

El 3 de abril de 1771, Toledo pidió al presidente de la Audiencia, don Pedro de Salazar, que se relevara de la administración de la renta en las diferentes provincias del reino a los gobernadores, alcaldes mayores y corregidores, y propuso sustituirlos por particulares.

\section{[...] el Director se ve muchas veces precisado a disimular lo que no debiera tolerar y a estudiar los términos con que escribirles por no exponerse a que le falten al decoro que le corresponde por su empleo, los particulares por el contrario estarían sujetos al Director, quien podrá escribirles con sequedad quando lo pidan las circunstancias de los acontecimientos sin recelo de que le respondan con altanería. ${ }^{3}$}

Desde su ascenso, Toledo se impuso la tarea de organizar la producción y combatir el contrabando que era común en toda la Audiencia, lo que significó un aumento considerable de empleados, principalmente guardias y visitadores. También se redujeron las áreas de siembra a cinco en todo el territorio de la Audiencia y hubo el proyecto de reducirlas a dos solamente: Simojovel y Costa Rica. ${ }^{4}$

En Chiapas - a diferencia de Copán, donde los productores eran españoles avecindados en Santiago (Antigua Guatemala) y los trabajadores eran suministrados por el Estado colonial mediante el "repartimiento"-, 5 la producción se llevaba a cabo en pequeñas unidades de trabajo familiar que cultivaban parcelas de tierras comunales de los indios de Simojovel. Sin embargo, a partir de 1811 cosecheros mestizos y probablemente criollos o españoles empezaron a participar de manera preponderante en la siembra, lo cual introdujo cambios en la estructura agraria municipal y en la composición social de la población local, como se argumenta en el presente artículo, en el que estudiaré cómo estaba organizado el monopolio a nivel local para responder a preguntas como: iquiénes formaban el grupo de cosecheros?, icómo operaba la burocracia a nivel local?, ¿cómo impactó la actividad en la transformación social del pueblo? A partir de 1811 los avíos y las mejores áreas de cultivo empezaron a ser acaparados por productores que operaban en una escala mayor a la implementada por los comuneros, y que procedían de regiones foráneas a juzgar por sus nombres y apelativos.

El tabaco, planta de la familia Solanaceae, la misma que los tomates, las papas, la mandrágora, el chile o la belladona —algunas de ellas muy peligrosas, otras alimenticias - convirtió a Simojovel durante la época señalada en un importante nodo al que concurrían viajeros y contrabandistas. Se consideraba que el tabaco que se producía en este municipio era de regular calidad, pero la empresa real lo vendía en las factorías y tercenas de la Audiencia debido a su bajo costo de producción, lo que permitía la obtención de mayores utilidades que las que obtenían por el tabaco de Copán, considerado de mejor calidad pero cuyo costo de producción y pago de fletes era mucho mayor. La posibilidad de hacer negocios con el tabaco u otras mercancías aprovechando la ubicación de Simojovel junto a un 
camino muy transitado que comunicaba Ciudad Real con Villahermosa, atrajo a las primeras familias de no indios al pueblo, tendencia que se acentuó durante la segunda mitad del siglo XIX, cuando proliferaron los denuncios de tierras baldías y se consolidó el despojo de las tierras comunales. ${ }^{6}$

\section{Simojovel a fines del periodo colonial}

A partir de 1766, año en que se estableció el Real Estanco del Tabaco en Guatemala, los habitantes de este pueblo ubicado en Los Altos de Chiapas se especializaron en la producción de esta planta, inicialmente junto a otros pueblos de las cercanías como Huitiupán y Plátanos; sin embargo, a partir de 1782 sólo los habitantes de Simojovel tenían permiso para sembrarla, como una medida para combatir el contrabando. Desde entonces, la importancia de Simojovel creció hasta convertirse en un importante nodo del comercio entre las tierras altas de Chiapas y la costa del Golfo de México. En 1785, la factoría de Ciudad Real contaba entre sus empleados permanentes con un comisario de siembras y varios guardias de pasos y caminos.

El comisario de siembras, que vivía en Simojovel, llevaba un estricto control de todo el proceso: repartía los avíos, relacionaba de manera detallada los nombres de cada uno de los productores y la cantidad recibida, vigilaba las plantas en los almácigos y su trasplante a las milpas calculando el número de manojos que se esperaba de cada productor, y llevaba cuenta de las plagas y las pérdidas por ellas provocadas, de las labores agrícolas y de la cosecha. Debía vigilar que los cosecheros formaran los manojos intercalando hojas de diferentes calidades y tamaños, sin adulterar con hojas de otras hierbas, palos o piedras; cuando esto último sucediera: "deberá dar cuenta al factor de la persona en quien se encontrare el defecto para que determine su castigo y sirva a los demás de escarmiento".?

Otra de las tareas que el comisario tenían encomendada era la formación de listas individuales en las que asentaba el número de manojos producidos por los productores y su calidad, lo que habían recibido de habilitación, lo que se les adelantaba de su liquidación, y los manojos de una y otra clase que adicionalmente produjeran, así como de la basura útil para la venta y del tabaco mal beneficiado y sin sustancia; en este último caso era preciso quemarlo o arrojarlo al río sin que por ningún motivo se permitiera dejar algo a los cosecheros: "por el perjuicio que esta tolerancia pueda generar a la renta".

El comisario también tenía que estar pendiente de que los indios de Huitiupán, Santa Catalina -o Catarina- y San Pedro evitaran sembrar la planta. ${ }^{8}$ Ninguna persona, de ninguna calidad estamental o laboral, podía producir, introducir, comprar o vender tabaco, sino que todo debía ser canalizado a través del estanco.

Los guardias del tabaco aplicaban la ley severamente, como Juan Zenteno, "guarda del paso de Vochil". En julio de 1784, este guardia, en complicidad con Antonio Estrada, un indio que fungía como maestro del coro de la iglesia de Pueblo Nuevo, acusó a un vecino, Gaspar Martín, de vender tabaco a escondidas, pretexto que le sirvió para efectuar un registro de todas las casas del pueblo, en el que encontró alrededor de cien hojas en la casa de Lucas Estrada, por lo que procedió a detener a la esposa de éste, Josefa Peñate, a la que encadenó a un cepo en la prisión de su hacienda de Bochil, donde le infligió latigazos hasta hacerla vomitar sangre, obligando de esta manera a Lucas a entregarse.

Zenteno se llevó presos también a Gaspar Martin y a Antonio Estrada, a los que encadenó al cepo al menos por veintidós días. Para defenderse, los comuneros apelaron al alcalde mayor de Tuxtla, Miguel del Pino, acusando a Zenteno de ser "un mal hombre [...] muy embustero y malo su corazón”, que les repartió ocho arrobas de algodón pero quería que le devolvieran a razón de diez arrobas hiladas. Amenazaban en su escrito con abandonar el pueblo en caso de que el alcalde mayor no remediara la situación. ${ }^{9}$

Como he mencionado, los alcaldes mayores formaban parte de una estructura burocrática y de poder diferente a la de la renta del tabaco, por lo que debieron dirigir su queja al factor del tabaco de Ciudad Real o al director general del mismo en la ciudad de Guatemala. No he localizado el documento que pone 
fin a la disputa, pero lo cierto es que en 1791 Zenteno seguía figurando como guardia del tabaco. ${ }^{10}$

Los guardias patrullaban los caminos continuamente y realizaban inspecciones en las cuevas de los montes. Por ejemplo, el 8 de diciembre de 1798 José Tomás Fagoaga, entre las 3 y las 4 de la mañana, salió al camino a esperar el paso de los indios de Simojovel que acudían al pueblo de Huitiupán a celebrar la fiesta de Nuestra Señora de la Concepción, y en su rondín atrapó a Pedro Mexia, que llevaba seis libras de tabaco para vender. Mexia fue sometido a proceso y declaró que contrabandeaba para "suplir sus necesidades". En esa misma época hay otros casos, por ejemplo, contra Mariano Pérez por siembras clandestinas, y contra indios de San Felipe por contrabando."

Otro ejemplo de cómo actuaban los guardias y comisarios se produjo el 22 de julio de 1800. Ese día, "estando en el registro de los montes y milperías de los naturales de este pueblo", los guardias Bernardino Guillén y Bernardino Camacho encontraron escondidos en varias cuevas localizadas cerca de las siembras de los guardias Isidoro Pontigo y Mariano Ancheyta, varios tercios de tabaco, de los que se rescataron 58 libras para utilidad del estanco y se incineraron 167 libras dañadas con la anuencia del gobernador intendente de la provincia Agustín de las Quentas Zayas. ${ }^{12}$

El comisario de siembras en el año 1802, don Lucas Vicente Toscano, decía que los indios de Simojovel eran muy inclinados a contrabandear tabaco:

Este pueblo es camino real a Tabasco y muy trajinado como tengo dicho, no puedo evitar que diariamente se alojen en el cabildo pasajeros de todas clases, y los más comunes son los indios de Zinacantán, que con motivo de pasar a Tabasco a traer cacao, y que suelen venderlo aquí, se mantienen en el cabildo uno o dos días. De noche hacen sus tratos con tanta cautela, que aunque yo y los guardas nos desvelemos, rara vez suele escucharse algo, porque el modo de tratarlo es que estando los zinacantecos, o cualesquiera otro indio con sus vendimias en el cabildo, van los indios y las indias a comprarles y en el iquenum [subrayado en el original] que tratan de comprar aquella vendimia, tratan también el tabaco, y el lugar y día donde lo han de ir a entregar. Salen los pasajeros a cualesquiera hora del día que todos los ven, nada llevan; pero a los tres o cuatro días vuelven por veredas a los lugares señalados, y aun hasta las milpas de los cosecheros a llevar el tabaco ¿Quién podrá evitar este agravio a la renta aunque lo comprenda? En unos montes tan cerrados quién va a adivinar donde están, a qué hora o qué día? ${ }^{13}$

\section{Los cosecheros de tabaco en las postrimerías del siglo XVIII y albores del XIX}

El nuevo siglo encontró a la renta con sus bodegas repletas de tabaco de Simojovel. El consumo en esos años había disminuido frente a la competencia de los tabacos procedentes de Tabasco, por lo que los almacenes de Ciudad Real y Quetzaltenango estaban atestados, lo mismo que las tercenas de la provincia, mientras que las vegas de Simojovel seguían produciendo.

A continuación se hace un análisis de la situación de los cosecheros de Simojovel en 1799, 1801 y 1811, a partir de documentos localizados en el Archivo General de Centroamérica, los cuales, debido a falta de espacio, no se transcriben completos aquí. Son los siguientes: ${ }^{14}$

1. Archivo General de Centro América (AGCA), Ch 3365, "Factura que justifica los tabacos que se han comprado a los cosecheros, y el dinero que se les satisfizo por su valor a cada interesado respectivamente en esta factoría de Ciudad Real el presente año de 1799".

2. Ciudad Real, 18 de octubre de 1799; AGCA, A3 (1), leg. 265, año de 1801, "Factura que justifica los tabacos que se les han comprado a los cosecheros en el año que arriba se expresa".

3. AGCA, A3, 13, leg. 2291, "Estado de la sementera de tabaco en el pueblo de Simojovel, abril 16 de $1811 "$.

En 1799 el grupo de cosecheros estaba compuesto por "168 indios naturales del pueblo de Simojovel". ${ }^{15} \mathrm{La}$ capacidad productiva de las unidades era pequeña, y 
para la mayoría el cultivo de tabaco era una actividad agrícola complementaria; solamente para algunos era su principal fuente de ingresos, de la que podían llegar a obtener hasta 102 pesos anuales o incluso más. De los 168, uno produjo un poco más de 900 libras, casi media tonelada; seis produjeron entre 400 y 600 libras (entre 181.6 y 272.4 kilogramos); nueve rebasaban las 300 libras (136.2 kilogramos); cincuenta producían entre 135 y 241 libras (entre 61.2 y 109.4 kilogramos) y el resto, 102 cosecheros, producían menos de 100 libras anuales (45.4 kilogramos). El 90\% de los cosecheros producía menos de 250 libras anuales. En conjunto produjeron 22961 libras de tabaco largo (94\% del total) y 1495 de tabaco corto o chanchán (6\%). En total fueron 11.1 toneladas entre ambas calidades (ver gráfica l).

El valor de la producción fue de 1481 pesos y seis reales. Desde 1785 el tabaco largo se pagaba "a los indios labradores a razón de 2 reales cada manojo de largo, a medio real el corto o chanchan y a 2 reales la libra de desecho o basura". ${ }^{16}$

Por lo anterior, el costo de producción, sin contar el costo de traslado, fue de 5333 pesos. Si a esta cantidad se descuentan los 1481 pesos y seis reales que obtuvieron los productores como pago final de su cosecha, se obtiene la cantidad adelantada, en forma de avíos, de 4352 pesos. El 95\% de los productores reportados en los documentos durante 1792 recibieron menos de veinte pesos de pago final (160 en total) y solamente ocho (5\%) estaban por encima de dicha cantidad. En términos generales, todos los cosecheros tenían muy baja capacidad y eran campesinos que con seguridad trabajaban directamente en sus sembradíos; pero había una pequeña fracción de ellos —ocho en total- que obtenía ingresos mayores que el resto, lo que podría interpretarse como que este sector se estaba especializando en el cultivo de la hierba. ${ }^{17}$

En el documento referenciado de 1792 consta el nombre de las personas, así como su pueblo de origen y la clasificación social en algunos casos. En este sentido, es interesante el hecho de que aparecen tres individuos clasificados como "ladinos": los hermanos Pedro, Domingo y Gerónimo de la Cruz, probablemente los primeros de esa categoría social en el pueblo. ${ }^{18} \mathrm{El}$ ladino es un tipo social que se formó con españoles empobrecidos, indígenas que habían abandonado sus comunidades de origen y vivían en los alrededores de las áreas urbanas y descendientes de esclavos negros (Macleod, 1980: 192).

Respecto al pueblo de origen, tres personas eran de Tila, una de Gueytiupán (Huitiupán), tres de Chilón, dos de Cancúc, una de Moyos, tres de Jitotol, una de Yajalón, dos de Sivacá y una de Pueblo Nuevo. ${ }^{19}$ Simojovel en esa época no solamente era un nodo en la ruta de comunicación entre las tierras altas de Chiapas y la costa del Golfo, sino también un centro urbano donde entraban en contacto individuos procedentes de diferentes afiliaciones culturales.

Otro dato interesante que proporciona indicios de estratificación social entre los productores de tabaco es el cargo que ocupaban o habían ocupado en el cabildo o en la iglesia como: gobernador del pueblo (Antonio Sánchez), dos escribanos (José y Francisco Hernández), dos fiscales (Francisco Hernández y Miguel Pasqual), el Pasado Mayor (Vicente Mexía), dos organistas (Pedro Hernández y Juan Jimenez) y un arpista (Diego Ximenez).

En diciembre de 1801, apenas dos años después, el número de cosecheros había crecido a 222, es decir, se había incrementado en un 32\%, y habían producido 88143 libras de tabaco largo y 9912 de corto - 44.5 toneladas en total- un incremento del $300 \%$ respecto a lo producido en $1799 . .^{20}$ Dado que el número de cosecheros solamente había crecido el $32 \%$, es probable que el incremento en la producción se deba a un ciclo libre de plagas, al mejoramiento técnico del proceso o a una combinación de ambos factores, además de a una mayor especialización entre las unidades productivas.

Para ese año, la capacidad de producción de las distintas unidades se había modificado: había disminuido considerablemente el sector que producía menos de cien libras y había crecido de forma significativa el número de productores medios y altos. El rango más alto, que producía entre 900 y 1350 libras, estaba ahora integrado por trece individuos; sin embargo, el mayor crecimiento se experimentó en el sector de rango medio 
(300-600 libras), que en 1801 constituyó casi el 50\% de los productores (ver gráfica 2).

El padrón de 1801 contiene una columna sobre los avíos recibidos por los productores, 2200 pesos en total, lo que permite saber con exactitud el ingreso de cada agricultor por vía del tabaco. Además del mayor número de cosecheros, hay otras importantes diferencias con respecto a 1799, que indican que el tabaco se había convertido en la principal actividad económica para la mayor parte de los agricultores de Simojovel. El 50\% de ellos percibía de 15 a 30 pesos anuales y casi el 20\% obtenía entre 31 y 50 pesos. El grupo de ingresos más altos, que recibía entre 50 y 90 pesos, estaba compuesto por diecinueve individuos (8.55\% del total). En otras palabras, el cultivo de tabaco estaba dejando de ser una actividad agrícola marginal y complementaria y se estaba convirtiendo en una actividad especializada que permitía a los campesinos diferenciarse económica y socialmente entre sí (ver gráfica 3).21

El incremento del número de cosecheros y la mayor productividad de las unidades condujeron a una saturación de la oferta. En la factoría de Ciudad Real se almacenaban 146213 libras (más de 66 toneladas), mientras en la factoría de Quetzaltenango había 2262 libras (una tonelada), además de las existencias de las diferentes tercenas repartidas en los pueblos de Chiapas y Guatemala. Por otra parte, el consumo anual llegaba a 30000 libras solamente (13.62 toneladas), es decir, había existencias para satisfacer la demanda durante un poco más de cuatro años, de tal manera que en 1802 se ordenó suspender la siembra. ${ }^{22}$

En el ínterin se hicieron propuestas técnicas para mejorar la calidad del producto, aumentar la productividad y disminuir costos; también se reorganizó la producción y, como consecuencia, en 1811 el número de productores había disminuido a 46 -el 27\% de los que había en 1799 y tan sólo el 20\% de los que había en 1801- A este grupo más pequeño se habían sumado cuatro productores cuyos nombres no corresponden con los nombres y apellidos de los "indios naturales del pueblo”; ellos son don José León Zumaeta, don Francisco Zamayoa, don Juan José Benavides y don José Manuel Parra, a quienes además el apelativo de "don" antecede a sus nombres. Estos cuatro cosecheros formaban dos unidades productivas, las cuales concentraron un poco más del $50 \%$ de las habilitaciones de ese año. Al reducirse el padrón, se redujo la cantidad erogada en habilitaciones a 613 pesos solamente. ${ }^{23}$

Los cuatro cosecheros con apellidos no indígenas no solamente acapararon la mayor parte de las habilitaciones, sino que cultivaron más plantas que cualquiera de los 42 restantes en solamente dos vegas (milpas), es decir, se trataba de plantaciones mayores, lo que hacía más eficiente el capital y el trabajo. No hay que dejar de señalar, además, que el comisario de siembras aparece en el padrón como uno de los que más cantidad de matas producía, con 10 599, superado entre los productores indios solamente por Bartolomé Rodríguez Mazán, que producía 12586 plantas y Marcos Pérez Ayocil, que producía 11913 plantas. ${ }^{24}$

Los cuatro cosecheros cuyos nombres indican un origen criollo o posiblemente peninsular recibieron en total de 312 pesos por concepto de habilitación (50.89\% del total), y entre ambas unidades cultivaron 62000 matas, lo cual representó el 25.44\% de las plantas sembradas ese año. Mientras tanto, los 42 cosecheros restantes, incluido el comisario de siembras, quien cultivaba cuatro milpas, recibieron en conjunto 301 pesos por el mismo concepto (49.11\% del total) y cultivaron 181701 matas (el $74.5 \%$ del total de matas de la temporada) en 69 milpas.

Aunque el grueso de los cosecheros seguía constituido por un conjunto de campesinos indígenas, en el grupo habían irrumpido los primeros agricultores "empresariales", que producían en mayor escala y eficiencia y acaparaban los avíos otorgados por el estanco. Dado que el cultivo de tabaco implica el uso intensivo de mano de obra, es probable que los campesinos que quedaron fuera del padrón con la reorganización productiva se emplearan entonces como jornaleros.

\section{El plan de Lucas Vicente Toscano}

En el año 1800 fue nombrado comisario de Siembras de Tabaco, con residencia en Simojovel, el señor Lucas Vicente Toscano, quien contribuyó a efectuar los ajustes 
en la organización de la producción mencionados líneas arriba, mediante un plan consistente en trasladar el cultivo a Acala y Chiapa de Corzo, donde se contaba con numerosa población indígena que podía dedicarse a estas labores. Toscano realizó observaciones climáticas y técnicas con base también en su conocimiento personal de los cosecheros y cargadores.

Entre las primeras medidas que tomó al llegar fue reparar la bodega, construida apenas cinco años antes, pero que el clima lluvioso de Simojovel había destruido, así como elaborar un informe sobre el estado de la actividad. En éste destaca que, además de las pérdidas ocasionadas por el clima, el estanco sufría mermas considerables debido al contrabando ya que: "los indios de Simojovel están muy viciados en contrabandear". ${ }^{25}$ El territorio estaba cubierto de impenetrables bosques tropicales que cobijaban las actividades ilegales de sus habitantes, quienes aprovechaban la costumbre de tener casas en las milpas, a las que iban de noche a dormir con el pretexto de velar sus siembras para evitar robos. Toscano dice que Simojovel tenía muchos pueblos circunvecinos cuyas milpas colindaban con las de los simojoveltecos, "y tanto estos como los otros indios duermen cuando quieren en sus milpas", por lo que:

[...] iquién podrá impedir que de noche por distintos rumbos extravíen el tabaco? Si me fuera fácil y lícito evitar a los simojoveltecos que fueran a dormir a sus milpas lo haría, pero resultarían dos perjuicios: el uno que los indios extraviarían el tabaco que es contra la renta y los cosecheros y el otro que también les roban sus maíces, frijol y otros granos que tienen en sus rancherías como ya ha sucedido a algunos. ${ }^{26}$

En su informe indica lo que considera defectos de la fuerza laboral. Dice Toscano:

[...] estos indios son desidiosos e incorregibles y no ponen el menor esmero en cultivar los tabacos, y con el pretexto de no hablárseles con la propiedad de su idioma, abusan, y desprecian cualesquiera albitrio o regla que se les comunica, y no hacen más que lo que ellos quieren, la calidad del producto deja mucho que desear. Los tendales donde maduran el tabaco son unas enramadas que no tienen resistencia alguna para librarle del agua, y si llueve el tabaco que está colgado madurándose se lava y el sol no le seca por la sombra. Las pilas o prensas las hacen en el suelo, y aunque debían estar estas al sol y al sereno no puede ser por precaverlas del agua. En fin, lo incorregible de los indios y la continuación de las lluvias, aun cuando el temperamento fuera caliente perfectamente haría bastante a impedir darle a los tabacos mejor beneficio, o calidad.

[...] Por otra parte, se advierte que los indios de Coronas y Chinampas que siempre han sacado tabaco de este pueblo a esa ciudad, están más renuentes y ya no quieren sacarlo, mayormente con el ejemplo de que los indios de Chamula consiguieron eximirse de esta función, y a más de venir forzados a sacarlo, el precio de seis reales que se les paga por cada tercio lo tienen por gravoso, por ser veinte leguas de asperísimo camino. De esta ciudad a las vegas dichas [Acala y Chiapa de Corzo] solo hay quince o diez y seis leguas de buen camino según me he informado con generalidad y pudiera conseguirse el que entrasen arrieros con mulas a sacar los tabacos y puede que a menos costo que de aquí; el buen camino haría que se brindasen conductores, ya que por malo este de Simojovel se niegan.

Este año pasado me dio Usted orden de que yo tratase los fletes con los indios conductores, y para descargo mío debo decirle que los indios de este Partido de Guardianías, como están bajo de mi mando no se resistieron a llevar cada tercio a los seis reales acostumbrados y con todo los de Moyos, ya le escribí a usted que querían a peso y por eso me mandó usted que los dejase y así lo hice. A los de Coronas y Sendales que vinieron a sacar tabaco, ya no les traté precio alguno porque al tiempo de tratarlo, a los indios de Chenaló, que fueron los primeros que llegaron al llamado, resultó que del hecho de contemplarles la voluntad, a que dijesen a qué precio querían por conducir cada tercio de tabaco, entendieron también que estaba en su albitrio el conducirlo o no, pues así que me pidieron un excesivo precio y que yo 
no accedí a él, me dijeron que no lo llevarían, y ya querían volverse sin sacar la carga, cuyo hecho si se les permitía iba a causar en los demás igual resistencia, y por esto me negué a la contemplación del trato de fletes, y les violenté a que llevaran el tabaco por el flete acostumbrado y me excusé ya de tratarlo con los demás, por no exponerme a otro tanto, y de aquí es que no se pudo tratar con ellos el flete como está mandado, ni ellos gozaron de este beneficio, porque son tan desconfiados y negados al trato civil de las gentes que es menester para que accedan aun en cosas que solo son en su beneficio, violentarles la voluntad; pues de otra manera nada se consigue de ellos [...]. ${ }^{27}$

Además, señala que las ventas de la factoría eran perjudicadas "por los tabacos que vienen de Tabasco de contrabando, porque los moradores de estas provincias se inclinan más a él que al del estanco por ser fuerte y de buen gusto". ${ }^{28}$ Según su informe, el tabaco ilegal provenía de Los Naranjos, El Blanquillo y San Carlos, "lugares extremadamente calientes, como lo es toda la provincia de Tabasco, no obstante las muchas lluvias que allí se experimentan y de aquí sale la consecuencia de que los tabacos buenos se dan en tierras calientes". ${ }^{29}$

La "incorregible" actitud de los indios advertida por Toscano parece ser una conducta intencional para boicotear una actividad que hasta ese momento a la mayoría les reportaba pocas utilidades. El bajo monto de los ingresos que les producía y la obligación de cultivar tabaco les impedía salir a jornalear, lo que los obligaba a contrabandear para obtener dinero en efectivo, de modo que se convertían en carne de presidio ya que las leyes y los guardias del tabaco eran implacables con ellos.

Al contrario de lo que sucedió en Nueva España y otros lugares, donde se generó una industria manufacturera para la elaboración de puros, cigarrillos y tabaco para inhalar y mascar, lo que dio origen a un temprano desarrollo industrial y obrero, en Centroamérica se disuadió esta vía y se mantuvo la industria del tabaco en un nivel técnico muy bajo, vendiéndose en rama para que los consumidores confeccionaran personalmente sus puros y cigarrillos o los dieran a hacer con mujeres, viudas o ancianos, el sector más vulnerable y pobre de la sociedad, quienes mantenían así su miseria. Es indudable que la actitud emprendedora de Toscano dio sus frutos, si no de manera radical — como hubiera sido lograr el traslado del cultivo a las vegas del Grijalva-, sí en lo referente a mejorar las condiciones técnicas, tales como el tamaño de las plantaciones, el número de vegas, la utilización de mano de obra asalariada y el mejoramiento del secado y fermentado, entre otros factores. Esto significó la llegada de plantadores empresariales.

\section{Conclusión}

A diferencia de otras regiones de la Audiencia como Copán y Costa Rica, donde los cosecheros lograron mantener mejores condiciones para producir tabaco una vez establecido el estanco en 1766, en Chiapas desde sus inicios la producción estuvo bajo el control férreo del Estado, que contaba con guardias que patrullaban los caminos a toda hora y vigilaban las milpas y a los productores, impidiéndoles cualquier desvío o contrabando; al mismo tiempo, ellos mismos se permitían ejercerlo o lo toleraban de contrabandistas profesionales que procedían de la costa del Golfo de México. A pesar de ello, algunos productores se arriesgaban a tratar de desviar algunas libras para venderlo de manera clandestina en las fiestas patronales de los pueblos.

El cultivo de tabaco generaba en Simojovel una derrama anual de efectivo a través de los avíos y finiquitos que recibían los productores de tabaco por parte del estanco. Estos productores constituían el sector económicamente más importante y demográficamente más numeroso, por lo que el cultivo de tabaco llegó a constituirse en la actividad agrícola especializada del pueblo, siendo el único en Chiapas, a partir de 1782, con permiso real de cultivar este producto. Tal condición lo ligó estrechamente a Ciudad Real, donde se localizaba la factoría de tabacos. En esa época, cada año cientos, quizá miles, de tsotsiles y tseltales trasportaban sobre sus espaldas las toneladas de tabaco producidas en Simojovel, sustituyendo a los transportistas y arrieros, que se negaban a transitar con sus mulas por tan áspero 
camino. Otros cientos de trabajadores originarios de Chamula, San Felipe, Zinacantán y Ciudad Real se desempeñaban como obreros en la factoría.

Durante la mayor parte del tiempo en que funcionó el estanco, el cultivo de tabaco en Simojovel fue una actividad marginal para la economía de los habitantes de la localidad, pero a partir de 1802 empezó a convertirse en la principal actividad económica, habiéndose especializado en ella un número considerable de campesinos, que obtenía con este producto la mayor parte de sus ingresos anuales. Esta condición generó cambios significativos en la estructura económica y social del pueblo y atrajo a los primeros plantadores no indios, quienes constituyeron unidades de producción más eficientes en el uso de la tierra, el capital y el trabajo, lo que originó las primeras propiedades privadas y dio inicio a la disolución de la propiedad comunal indígena de la tierra, proceso que se consolidó en la segunda mitad del siglo XIX.

\section{Notas}

${ }^{1}$ En el caso de Nueva España, durante la segunda mitad del siglo XVIII constituyó el segundo rubro de la economía, tan sólo por debajo de la minería.

2 AGI, Signatura Guatemala, 775. "Año de 1768, Testimonio adjunto, incluye el nombramiento que hice de director..."

${ }^{3}$ AGI, Signatura Guatemala, 775. "Año de 1768, Testimonio adjunto, incluye el nombramiento que hice de director..." Tiburcio Ángel de Toledo se hizo cargo de la Dirección General de la Renta del Tabaco el l de noviembre de 1768 a raíz de los graves achaques por enfermedad de Francisco Valdés. Entró al servicio burocrático en 1761, como alcalde mayor de los partidos de Totonicapán y Huehuetenango: "importaban sus tributos diez mil quatrocientos setenta y cinco pesos un real al año" y en 1766, cuando dejó de ser alcalde mayor, "montaban sus tributos al año once milquatrocientos veinte y cinco pesos y seis reales" (AGI, Signatura Guatemala 775, Testimonio del título de Director General de la Renta del Tabaco...).

4 1786, AGI, Legajo Guatemala 778, Testimonio del expediente instruido a consultas del Contador General de la renta del tabaco, sobre que se reduzcan todas las siembras de esta especie para el consumo del Reino precisa y exclusivamente a esta Provincia de Costa Rica, Juan del Barrio, Director General de la Renta del Tabaco. Es una propuesta de producirlo en los alrededores templados de Cartago y llevarlo por tierra a Punta Arenas y de allí en barcos al Realejo, Nicaragua y Sonsonate, El Salvador, plazas desde las que se repartiría al resto del territorio a través de rutas terrestres y fluviales, controladas por transportistas privados.

5 AGCA, A 313, exp. 31149, “Año de 1806, Expediente en que los Yndios del Pueblo de Lepaera se quejan del mal tratamiento y demás, que reciven de los cosecheros de tabaco". Acuña Ortega también reporta que los cosecheros de Costa Rica presentaron resistencia inicial al estanco debido a la caída de los precios que esto supuso (Acuña, 1974: 289).

${ }^{6}$ En 1837, mucho tiempo antes de que se sembrara allí la primera mata de café, había en el Departamento de Simojovel 41 propiedades rústicas, con un valor de 50175 pesos (Memorias e informes de los gobiernos de Chiapas 1826-1900, año: 1888-1889, Anexo III documentos, sección fomento; imagen: 99 CUIDUNICACH, núm. 79. "Secretaria general de gobierno del estado de Chiapas, cuadro estadístico demostrativo, de las propiedades rusticas y urbanas en el estado, sus valores aproximados, así como el del giro mercantil, en su orden progresivo desde el año de 1837 hasta el 30 de junio de 1889").

${ }^{7}$ AGCA, Expediente Ch 03455, "Año de 1802. Respuesta sobre nuevo plan de siembras en la Factoría de Ciudad Real por don Lucas Toscano".

8 "[...] en caso de que se encuentre alguna siembra por corta que sea se deberá destruir y quemar aprehendiendo al dueño y se dará cuenta al factor para que determine el castigo a tan grave delito". La prohibición debía aplicarse también en "las haciendas y ranchos que se hallen situados en las inmediaciones de Simojovel y Plátanos, quemándolos y destruyéndolos y tomando presos a sus dueños" (AGCA, Ch 03035, 1786, "Obligación que debe observar don Gregorio León de Ocampo, comisario de la renta de tabaco en los pueblos de Simojovel y Plátanos, cuyos vecinos son 
los únicos a quienes se les permite por ahora en esta provincia de Chiapa licencia para que siembren tabaco de cuenta de la real hacienda". En algunos casos, como éste, la información tiende a ser contradictoria pero es probable que pese a la disposición oficial de 1782, de permitir el cultivo de tabaco solamente en Simojovel, se siguiera permitiendo su cultivo también en Plátano o se permitiera ocasionalmente.

9 AGCA, Signatura A-3 (1), leg. 243, exp. 3033, "Autos contra don Juan Zenteno y otros individuos por querella puesta por los indios de Pueblo Nuevo Solistaguacán en la provincia de Tusta de las Chiapas, año de 1784".

${ }^{10}$ AGI, Guatemala, 780, f. 113, "Plano de los empleados actuales que tiene la Renta del Tabaco de este Reyno de Guatemala con distinción de los destinos que obtienen, sueldos que gozan y departamentos donde sirven".

${ }^{11}$ AGCA, Ch 03362, 1798,A3.13(I), "Contra Pedro Mexia; 1798"; Ch, 262, 03363, "Contra Antonio Pérez, indio de Simojovel, por siembras clandestinas; Diligencia seguida para comprobación de cinco libras de tabaco rama Simojovel que aprehendió el visitador don José Mariano Tarazona en el camino a san Phelipe, aun [sic] indio que no pudo alcanzar".

${ }^{12}$ AGCA, Ch, 3404. "1800. Sobre cincuenta y ocho libras de tabaco decomisadas en las inmediaciones del pueblo de Simojovel por el resguardo de la factoría de Ciudad Real".

13 AGCA, Ch, 03455, "Año de 1802. Respuesta sobre nuevo plan de siembras en la Factoría de Ciudad Real por don Lucas Toscano". Los indios del pueblo y de otros pueblos circunvecinos contrabandeaban tabaco de Simojovel, pero no está claro quiénes lo hacían desde los ríos y lagunas de la costa del Golfo, aunque es probable que se tratara de tabasqueños.

${ }^{14}$ Dichos documentos contienen el padrón de cosecheros de tabaco del pueblo de Simojovel, con los nombres completos de los productores, la cantidad de matas cultivadas, el avío recibido y la cantidad recibida como finiquito, el número de milpas o vegas que cultivaba y su categoría social.

${ }^{15}$ AGCA, Ch 3365, "Factura que justifica los tabacos que se han comprado a los cosecheros, y el dinero que se les satisfizo por su valor a cada interesado respectivamente en esta factoría de Ciudad Real el presente año de 1799".

${ }^{16}$ AGCA, Sig A3 /3, leg. 339, Chiapas (1), "Año de 1792". En la época, un manojo equivalía a una libra de 17.5 onzas. En realidad los números no cuadran del todo ya que, aplicando estos precios de compra, la cantidad que resulta parece excesiva, sobre todo en lo referente a avíos.

${ }^{17}$ AGCA, Sig A3 /3, leg. 339, Chiapas (1), "Año de 1792".

${ }^{18}$ AGCA, Sig A3 /3, leg. 339, Chiapas (1), "Año de 1792".

${ }^{19}$ AGCA, Ch 3365, "Factura que justifica los tabacos que se han comprado a los cosecheros, y el dinero que se les satisfizo por su valor a cada interesado respectivamente en esta factoría de Ciudad Real el presente año de 1799".

${ }^{20}$ Ciudad Real, 18 de octubre de 1799; AGCA, A3 (1), leg. 265, año de 1801, "Factura que justifica los tabacos que se les han comprado a los cosecheros en el año que arriba se expresa".

${ }^{21}$ Ciudad Real, 18 de octubre de 1799; AGCA, A3 (1), leg. 265, año de 1801, "Factura que justifica los tabacos que se les han comprado a los cosecheros en el año que arriba se expresa".

${ }^{22}$ AGCA, Expediente Ch 03455, "Año de 1802, Ciudad Real. Sobre que se suspenden para este año las siembras de tabaco en Simojobel".

${ }^{23}$ AGCA, A3, 13, leg. 2291, "Estado de la sementera de tabaco en el pueblo de Simojovel, abril 16 de 1811".

${ }^{24}$ AGCA A3. 13, leg 2291, "Estado de la sementera de tabaco en el pueblo de Simojovel, abril 16 de 1811".

25 AGCA, Ch, 03455, "Año de 1802. Respuesta sobre nuevo plan de siembras en la Factoría de Ciudad Real por don Lucas Toscano".

${ }^{26}$ AGCA, Ch, 03455, "Año de 1802. Respuesta sobre nuevo plan de siembras en la Factoría de Ciudad Real por don Lucas Toscano".

${ }^{27}$ AGCA, Ch, 03455, "Año de 1802. Respuesta sobre nuevo plan de siembras en la Factoría de Ciudad Real por don Lucas Toscano".

${ }^{28}$ AGCA, Ch, 03455, "Año de 1802. Respuesta sobre nuevo plan de siembras en la Factoría de Ciudad Real por don Lucas Toscano". 
${ }^{29}$ AGCA, Ch, 03455, "Año de 1802. Respuesta sobre nuevo plan de siembras en la Factoría de Ciudad Real por don Lucas Toscano".

\section{Referencias}

Acuña Ortega, Víctor Hugo (1974). Historiaeconómica del tabaco. Época colonial. Tesis para obtener el título de Licenciado en Historia, Universidad de Costa Rica, San José.

Deans-Smith, Susan (2014). Burócratas, cosecheros y trabajadores. La formación del monopolio del tabacoen la Nueva España borbónica. México: Universidad Veracruzana.

Del Carpio Penagos, Carlos Uriel (2014). "Cultivo, calidades y precio del tabaco en Centroamérica a fines del periodo colonial". En Liminar. Estudios Sociales y Humanísticos, XII(2), julio-diciembre: 195-208.
Del Carpio Penagos, Carlos Uriel (2016). “Organización de la producción de tabaco en Centroamérica y Chiapas a fines del periodo colonial". En Agustín Hernández Ceja y Estela Zárraga, Chiapasy Jaliscoentresiglos. Guadalajara, México: Universidad de Guadalajara, pp. 13-30.

Macleod, MurdoJ.(1980). Historiasocio-económicadela América Centralespañola, 1520-1720. Guatemala: Piedra Santa.

Luján Muñoz, Jorge (2001). "El establecimiento del Estanco del Tabaco en el Reino de Guatemala". En Mesoamérica, 41(22): 99-136.

Pérez Castro, Ana Bella (1989). Entre montañas y cafetales. México: UNAM.

Quesada Saldaña, Flavio José (1980). Estructuración $y$ desarrollo de la administración política territorial de Guatemala en la coloniay la época independiente. Guatemala: USAC. 
Grafica 1. 1799, Cosecheros de tabaco de Simojovel. Tamaño de las unidades según libras producidas

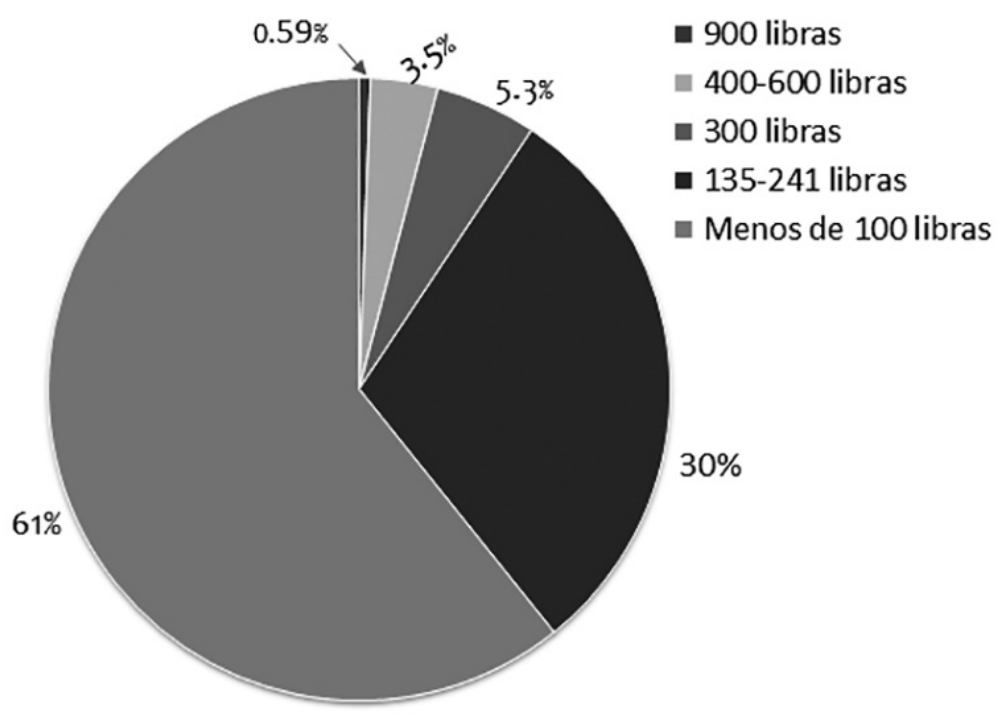

Fuente: datos obtenidos de AGCA, ch. 3365.

Grafica 2. 1801. Cosecheros de tabaco de Simojovel. Tamaño de las unidades según libras producidas

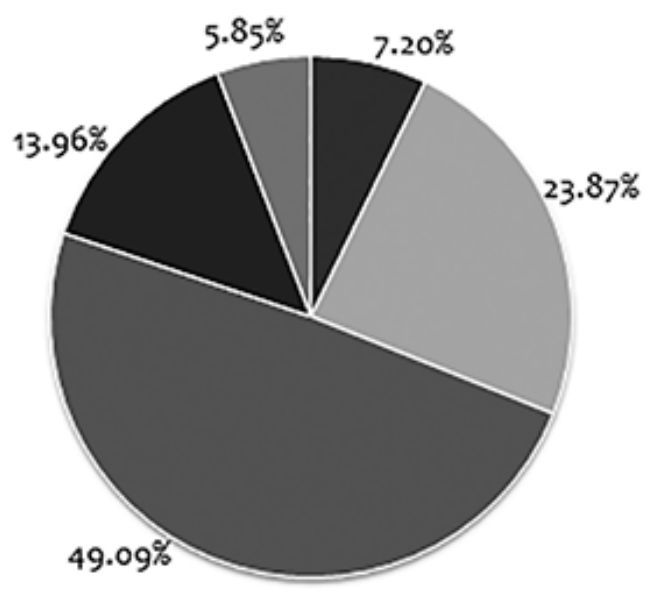

a Menos de 100 libras

=100-300 libras

- 300-600 libras

- 600-900 libras

• Más de goo libras

Fuente: datos obtenidos de AGCA, A3(I), leg. 265, año de 1801. 
Gráfica 3. 1801. Cosecheros de tabaco de Simojovel según ingresos

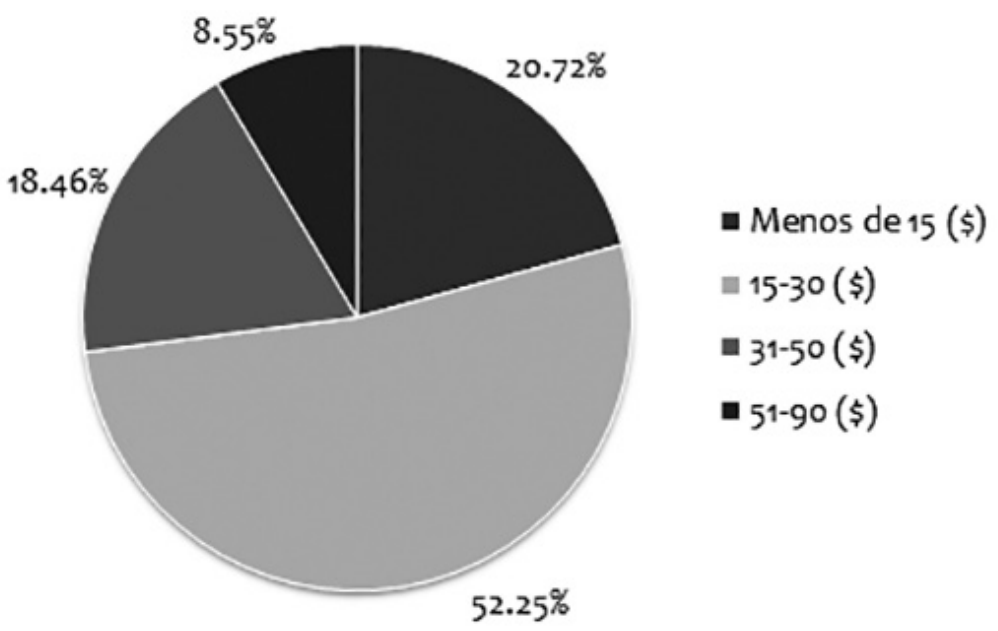

Fuente: datos obtenidos de AGCA, A3(I), leg. 265, año de 1801. 